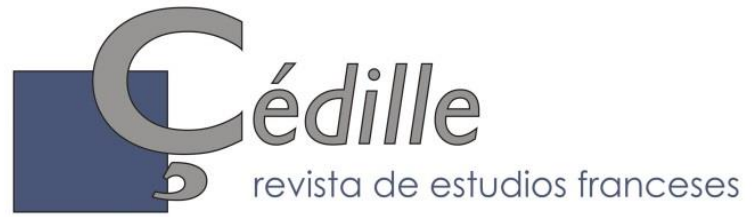

ISSN: 1699-4949

no 20 (otoño de 2021)

Varia

\title{
Franceses y españoles en el Cádiz de 1700 a tra- vés de Voyages du P. Labat des FF. Prescheurs en Espagne et en Italie
}

\author{
Lourdes RUBIALES BONILLA \\ Universidad de Cádiz \\ lourdes.rubiales@uca.es \\ https://orcid.org/oooo-0oo2-1461-8878
}

\section{Resumen}

A partir del volumen que Jean-Baptiste Labat (1663-1738) dedica a su estancia en España en sus Voyages du P. Labat des FF. Prescheurs en Espagne et en Italie (1730a), en este trabajo exploraremos algunas pistas biográficas, históricas y literarias para comprender la relación del autor con España, así como la representación de las relaciones franco-españolas que se desprende de su relato. Centrándonos sobre todo en lo que une más que en lo que separa a franceses y españoles, nuestro objetivo será poner de relieve los elementos que interfieren en el dispositivo aparentemente estable que opone el «Nosotros» al «Ellos» en el discurso de Labat.

Palabras clave: Viajeros franceses. Representaciones. Alteridad. España. Francia. Siglo XVIII.

\section{Résumé}

En partant du volume que Jean-Baptiste Labat (1663-1738) consacre à son séjour en Espagne dans Voyages du P. Labat des FF. Prescheurs en Espagne et en Italie (1730a), cette étude propose l'exploration de quelques pistes biographiques, socio-historiques et littéraires pour comprendre le rapport de l'auteur à l'Espagne ainsi que la représentation des relations franco-espagnoles découlant de son récit. En nous centrant sur ce qui unit plutôt que sur ce qui sépare les Français et les Espagnols, il s'agira de faire ressortir les éléments qui interfèrent dans le dispositif apparemment stable opposant le «Nous» au «Eux» dans le discours de Labat.

Mots clé: Voyageurs français. Altérité. Représentations. France. Espagne. XVIII siècle.

\begin{abstract}
Our point of departure shall be the volume in which Jean-Baptiste Labat (1663-1738) devotes to his stay in Spain in Voyages du P. Labat des FF. Prescheurs en Espagne et en Italie (1730a). In this light, our paper shall explore some biographical, sociohistorical and literary clues in order to understand the author's relationship with Spain as well as the representation of the relationships between
\end{abstract}

*Artículo recibido el 16/04/2021, aceptado el 28/05/2021. 
Spanish and French communities in his account. With a focus on what unites rather than on what separates both communities, our purpose is to highlight the elements interfering with the apparently stable opposition between «We» and «They» in Labat's discourse.

Keywords: French travelers. Representations. Otherness. France. Spain. $18^{\text {th }}$ Century.

\section{Introducción}

El religioso dominico Jean-Baptiste Labat (París, 1663-1738) es sobre todo conocido por su Nouveau voyage aux isles de l'Amérique [...] (1722a), voluminosa obra que se presenta como un tratado clásico de Historia Natural, pero que recoge asimismo, en primera persona, las vivencias del autor en el Caribe francés, entre 1693 y 1705. A su vuelta, de camino a Marsella -desde donde debía trasladarse a Bolonia para asistir al Capítulo General-, Labat hizo una obligada escala en Cádiz a la que dedica el primero de los ocho tomos que componen los Voyages du P. Labat des FF. Prescheurs en Espagne et en Italie, publicados en $1730^{1}$. Aunque de menor repercusión que la primera, esta obra (y concretamente, en lo que aquí nos interesa, el tomo dedicado a España) ha sido objeto de varias reediciones y adaptaciones y de una traducción al español ${ }^{2}$.

En el ámbito académico, el relato del viaje español de Labat no ha suscitado un interés comparable al de otros textos de viajeros franceses por la España de la Edad Moderna, como es el caso del clásico de Mme d'Aulnoy (1651-1705) Relation du voyage en Espagne (1691). Este (relativo) desinterés por el texto de Labat puede deberse, en primer lugar, al carácter local y circunstancial del viaje, lo que parece restarle valor de representatividad para los estudios que se han interesado, en las últimas décadas, por la «imagen» de España en los relatos de viajeros foráneos; en segundo lugar, también puede estar relacionado con las propias características del relato, que no responde a un proyecto de relación metódica de los lugares visitados sino que parece más bien un intento de alargar unas notas mediante numerosas digresiones, extensas referencias librescas y alguna que otra peripecia; por último, no puede obviarse una cierta reputación del religioso como autor

\footnotetext{
${ }^{1} \mathrm{Al}$ margen de estas dos obras, Labat compuso otras varias sobre viajes que no había realizado y que la crítica no considera en general como obras originales. Es el caso de la Nouvelle relation de l'Afrique Occidentale, contenant une description exacte du Sénégal et des Païs situés entre le Cap-Blanc et la rivière de Serrelienne [...] (1728) o Voyage du Chevalier Des Marchais en Guinée, Isles voisines, et à Cayenne [...] (1730).

${ }^{2}$ La última reedición de este texto es, que sepamos, la de la editorial Renacimiento, titulada Viaje por Andalucía (2007). Esta reedición retoma la traducción ya antigua de García Mercadal (1952) que, lamentablemente y como pone de manifiesto Irene Aguilà en un detallado estudio, contiene numerosos errores, omisiones, calcos y modificaciones con respecto al texto fuente (Aguilà, 2007).
} 
poco serio, superficial y fabulador, que no merece la credibilidad de otros autores 3 . Ya en 1770, en su Voyage de France, d'Espagne, de Portugal et d'Italie, Etienne de Silhouette (1709-1767) escribía sobre una reedición de los Voyages de Labat:

Il vient de paroître assez récemment une relation d'Italie \& d'Espagne en huit volumes in-12 dont le Père Labat, Dominicain, est l'Auteur. Ce bon Père raconte éternellement ; il entreprend assez souvent l'histoire des villes, rarement il la finit : il a presque toujours copié de trèsmauvais Auteurs ; si, au reste, il a le défaut d'endormir, défaut assez ordinaire, il a un talent qui lui est particulier ; c'est de réveiller de tems en tems par des traits assez grotesques ; sa relation est faite à la hâte, \& c'est le moins qu'on en puisse dire (Silhouette, 1770, t. I: 7-8).

No es difícil reconocer, en las palabras de Silhouette, uno de los lugares comunes del género, a saber, el desprestigio de los testimonios anteriores en cuanto a la exactitud, la amplitud o la profundidad con la que se da cuenta de un país o de un territorio y del «carácter» de sus habitantes. Así, añade Silhouette:

La plupart de ceux qui ont fait des relations de l'Espagne, n'ont pas, je crois, senti la difficulté qu'il y a de réussir. Ils se sont moins appliqués à faire connoître les Espagnols, qu'à les injurier. La relation de Mme d'Aunoy est remplie d'aventures, qui la rendent moins semblable à une relation qu'à un roman. Le Père Labat, dans un ouvrage intitulé, Voyage en Espagne \& en Italie (sic), ne parle que de Cadix, de Gibraltar \& de Séville. Ce Père fait le railleur; mais ses plaisanteries ne sont pas toujours ni bienfaisantes, ni heureuses, ni justes (Silhouette, 1770, t. III: 2 ).

Pero más allá del tópico de género, las afirmaciones de Silhouette sobre el texto de Labat prefiguran un discurso que encontramos de manera recurrente entre los hispanistas franceses de finales del siglo XIX y principios del XX pero que los intelectuales españoles habían difundido desde siglos atrás, sobre la «imagen» de España en el país vecino, discurso que se

\footnotetext{
3 No obstante lo anterior, justo es mencionar una serie de estudios, además del arriba citado sobre la traducción, que han abordado el texto que aquí nos ocupa. Por orden cronológico, «Le voyage du Père Labat en Andalousie» de Jean Sarrailh (1963), el primero quizá de cierta enjundia consagrado a este texto; «Le P. Labat en Espagne. Le récit d'un séjour involontaire» de Inmaculada Tamarit (2006), un estudio que pone el acento en la representación negativa de España y los españoles que se desprende del mismo; y «L regard porté sur Cadix et Séville par l'abbé de Vayrac et le père Labat» de Jean René Aymes (2017), que tiene el interés doble del comparatismo entre dos visiones de dos ciudades rivales en la misma época. A estos trabajos se añade nuestro estudio sobre la cuestión editorial: «Viaje por Andalucía ou La traversé éditoriale d'un récit de voyage» (2011) al que nos referiremos más adelante.
} 
resume en una queja: los extranjeros -y, en particular, los franceses- no se interesan por España y cuando lo hacen, se limitan a generalizar, exagerar o inventar defectos del «carácter» nacional con ánimo denigratorio. La «leyenda negra», término popularizado por Julián Juderías a principios del siglo XX, es la expresión más acabada de este discurso que sobrevive, a pesar de haber sido cuestionado por una parte de la historiografía actual (García Cárcel, 1992), en no pocos estudios sobre la «imagen de España» en el extranjero. De hecho, la cuestión de la leyenda negra antiespañola ha conocido un significativo rebrote en los últimos años, llegando incluso a constituir best-sellers, como el controvertido Imperofobia y leyenda negra de Elvira Roca (2016)4.

Volver sobre la cuestión de la «imagen de España» en la literatura de viajes puede suscitar, de entrada, una cierta aprensión dado el volumen de estudios que la han tomado como objeto, con mayor o menor fortuna, en las últimas décadas. Sin embargo, este trabajo pretende, precisamente, cuestionar la validez explicativa del paradigma dominante en este tipo de estudios. Nos referimos al paradigma que, basado en la oposición Yo vs Otro, no solo parte de una lógica dicotómica, al mismo tiempo simplista y rígida, sino que además presupone la existencia de un «Otro» que el crítico constituye, $a$ priori, como tal, es decir, como un «No-yo» radical. Ahora bien, como observa Pierre Halen, «celui dont la parole est accessible [...], celui avec lequel une histoire commune peut ou non s'engager, c'est Autrui, ce n'est pas l'Autre, lequel m'est, littéralement, aliéné». Por lo tanto, «recourir à ce terme d' "Autre» lorsqu'on entend, en réalité, faire place à Autrui et à sa parole est au moins introduire inutilement une ambigüité» (Halen, 1999: 48).

La cuestión del «Otro» está íntimamente ligada al concepto -tan recurrente como confuso en la crítica literaria- de exotismo. Para definir este concepto, Halen parte del hecho de que la percepción de los demás (sírvanos como traducción de "Autrui») y, por ende, el discurso sobre los demás, se construye sobre la base de la diferencia y de la identidad, en proporciones variables y según múltiples factores. Esto no es óbice, sin embargo, para que, en determinadas circunstancias, la mirada del sujeto solo perciba, en esa comunidad humana que es objeto de su discurso, lo que en ella hay de diferente, de extraño: se trataría de la mirada alterificadora propia del exotismo que Halen define, grosso modo, como el discurso que transforma a «Autrui» en "Autre», es decir, en una entidad exterior, lejana y, en último extremo, innaccesible u opaca; y esto -es importante subrayarlo- con independencia de la coloración peyorativa o meliorativa de dicho discurso. Halen propone el término de «antexotismo»-nosotros preferimos denomi-

\footnotetext{
4 Sobre esta temática, véase igualmente: Leyendas negras. Vida y obra de Julián Juderías de Luis Español (2007), La leyenda negra de Joseph Pérez (2009), Sobre la leyenda negra de Iván Vélez (2014), 1492: España contra sus fantasmas de Pedro Insúa (2018), o La leyenda negra. Historia del odio a España de Alberto Ibáñez (2018).
} 
narlo «endotismo»- para el discurso que, a la inversa, supone que esa porción de humanidad es, si no totalmente, al menos en parte, accesible al observador y con la cual le es posible construir o imaginar una historia común (Halen, 1999: 53).

Por su naturaleza pasajera, la experiencia viática no crea las condiciones propicias para la relación endótica, que sería lo propio del asentamiento -más o menos prolongado-y que adquiere su expresión extrema en la figura del «asimilado». Sin embargo, no es posible adscribir un tipo de experiencia -viática o residencial- a un solo tipo de relación -exótica o endótica- ya que esta depende de otros factores susceptibles de modular el encaje del «Yo», viajero o residente, y el «Ellos», autóctonos. De hecho, exotismo y endotismo raramente se dan en estado puro ya que, si el exotismo total confinaría al silencio - puesto que con lo radicalmente diferente no hay posibilidad de comunicación-, el endotismo total supondría la abolición de la alteridad, la disolución completa de la diferencia.

A la luz de estas consideraciones, en este trabajo no se tratará de presentar un simple repertorio de «imágenes» a las que Labat recurre para construir su discurso sobre España y los españoles. Nuestro propósito será más bien la exploración de algunas pistas -biográficas, sociohistóricas, literarias - para comprender la relación de Labat con España y la representación de las relaciones franco-españolas que se desprende de su relato. Poniendo el foco de interés más sobre lo que une que sobre lo que separa, trataremos de poner de relieve una serie de elementos que interfieren en el dispositivo aparentemente estable que opone el «yo/nosotros» («nos», «notre», «chez nous», «la France», etc.) al «ellos» («l'Espagne», «les Espagnols», «les Cadisiens», «ces gens-là», etc.) en el discurso de Labat.

\section{Un religioso peculiar}

En nuestro estudio sobre la «travesía editorial» del relato español de Labat (Rubiales, 2011), intentamos mostrar cómo la obra de este religioso ha sufrido un proceso de reclasificación en la historia literaria, es decir, se trataría de textos que no fueron concebidos ni recibidos como literarios en su época pero que se presentan y se leen en la actualidad como relatos de aventuras. En correlación, el propio Labat, considerado entonces como un religioso erudito, se nos presenta en las reediciones modernas de su obra como un potente narrador y como uno de los principales atractivos, en tanto que personaje, de sus historias. Este desplazamiento del estatus de la obra y del autor sería, al menos en parte, el resultado de un trabajo sistemático 
de selección de determinados capítulos o extractos de sus obras en detrimento de otros 5 y de la inclusión de un aparato paratextual destinado a realzar, incluso a exagerar, ciertas facetas del autor, en detrimento de otras, menos atractivas para el lector contemporáneo ${ }^{6}$.

Con todo, en la época del «renacimiento» literario del autor, no todos se mostraron conformes con la imagen de un Labat descargado del peso de la fe y de la erudición y convertido en un escritor liviano, en un aventurero heterodoxo. En particular los círculos religiosos criticaron el carácter tendencioso de la edición de los Voyages que hizo el escritor franco-belga Albert t'Serstevens (1885-1974) en 1927 y cuyo título, La Comédie ecclésiastique, es ya indicativo del carácter que se quiso dar a esta publicación. El dominico Marie-Dominique Constant, por ejemplo, se lamentaba de la parcialidad que subyacía en la selección de textos para esta edición y en la presentación sesgada que hacía t'Serstevens del religioso. Constant deploraba igualmente la publicidad frívola que el editor Bernard Grasset hizo del libro, presentándolo a los lectores como la «truculenta historia de un fraile vagabundo» (Constant, 1927: 293). Sea como fuere, la imagen de Labat que se

5 Cierto es, por un lado, que a su faceta erudita se le reprocha falta de rigor o se la considera envejecida desde el punto de vista científico y, por otro lado, que, como observa Henri Stehlé, el carácter «aplicado» de su saber le confiere un estatus menor con respecto a la ciencia «desinteresada», a la botánica «pura» de un Plumier (Charles Plumier, 1646-1704), célebre naturalista y botánico francés con el que Labat había coincidido en las islas y que, casualmente, murió en el Puerto de Santa María un año antes de la llegada de este a Cádiz (Stehlé, 1977: 423).

${ }^{6}$ Esta perspectiva requiere, al menos, dos importantes matizaciones. En primer lugar, si parece evidente que las ediciones modernas de los textos de Labat han operado en el sentido de una «literarización» de los mismos, no es tan evidente que dichos textos no fueran concebidos ni recibidos como literarios en la época. Una mirada más atenta al contexto de producción de esta categoría de textos que constituyen los relatos de viajes, en boga entre los siglos XVI y XVIII en Europa, muestra que tal transformación de los textos de Labat solo ha sido posible, precisamente, porque lo «literario» está inscrito en el propio género, tal como ha mostrado la crítica en las últimas décadas (ver, entre otros, Ouellet, 2009; Pioffet, 2011; Motsh, 2014). En segundo lugar, es probable, como afirmábamos, que fuera el escritor anglo-griego Lafcadio Hearn (1850-1902) quien despertara el interés por Labat en Francia, sobre todo tras la traducción al francés, en 1924, de Two years in the French West Indies (1890) con el título de Esquisses martiniquaises. A partir de ahí se suceden varias reediciones de sus obras, abreviadas y adaptadas al gusto de los lectores contemporáneos (y a los estándares de la edición moderna) y se modela, por así decir, el «nuevo Labat». Sin embargo, ya en la reedición de Nouveau voyage aux isles de l'Amérique publicada en 1831 puede observarse una manipulación del texto original del que se habían «abreviado» ciertos textos técnicos que no ofrecían el interés de antaño, según reza en la introducción no firmada ni paginada de la edición en cuestión. En cambio, el autor de la introducción señala, como punto fuerte, «une foule de petites anecdotes, la plupart malignes» que conservaban todavía un «un intérêt le plus piquant» (in Labat, 1722b: n/p). Labat -continúa el texto- «instruit et amuse beaucoup» a la par que, todo hay que decirlo, reconfortaba un sentimiento anti-criollo, extendido en la época. Esto quiere decir, pues, que el proceso de «literarización» apuntaba ya a principios del siglo XIX. 
desprende de la mayoría de las referencias biográficas consultadas -incluidas las más ortodoxas- y, sobre todo, la que emana de sus propios escritos, es la de un religioso cuando menos poco convencional. Así, por ejemplo, en la nota del historiador Albert Hyrvoix de Landosle (1848-1931), que sirve de introducción a una reedición «seria» de la parte española de los Voyages (que llevó por título Voyage en Espagne, 1927), el autor cita un artículo de Année Dominicaine de 1912 en el que se afirmaba que: "Ce religieux mena toujours une vie parfaitement religieuse, sans pour autant se distinguer par une sainteté extraordinaire... Il brilla plutôt par les dons supérieurs de l'intelligence que par des vertus remarquables» (apud Hyrvoix de Landosle, in Labat, 1730c: 14).

Sin llegar al extremo de t'Serstevens, para quien Labat roza la herejía, los biógrafos coinciden en la idea de que el autor no se ajustaba al modelo del religioso o del sabio asceta. Para Lafcadio Hearn, por ejemplo,

Ce n'est pas un moine humble et timide : il a la nature et l'humeur d'un de ces abbés du moyen âge qui revêtaient avec une égale indifférence casque ou capuchon. Il semble même être plus soldat que prêtre; et lorsque des corsaires anglais tentèrent de débarquer sur la côte martiniquaise à Sainte-Marie, ils trouvèrent le Père Labat qui les attendait, entouré de tous les nègres de la plantation Saint-Jacques pour les repousser jusqu'à leurs navires (Hearn, 1890: 81-82).

Labat encarna así el modelo medieval del monje guerrero porque escribe t'Serstevens- «[...] il semble toujours porter une épée sous sa robe et des pistolets à la place de son rosaire» (in Labat, 173ob: 34). Esto le ha valido pasar a la historia como el «capellán de los filibusteros», fórmula que ha hecho fortuna en la reactualización de su obra en el siglo XX7.

Por otra parte, su personalidad enérgica, su aguda inteligencia y su versatilidad en los campos del saber y de la acción hacen de él un personaje peculiar y difícil de describir si no es través de enumeraciones, como la que incluye Michel Le Bris en su presentación de Voyage aux Isles. Chronique aventureuse de la Caraïbe $1693-1705^{8}$, inspirada muy de cerca en las que en su día hicieran Lafcadio Hearn (1890), Joseph Rennard, (1926), t'Serstevens (1927 y 1931, in Labat, 1730b y 1722c) o Lavigne de Saint Suzanne (1935):

Il est dix hommes à lui tout seul, courant d'île en île, tour à tour ingénieur, architecte, botaniste, médecin, soldat, corsaire, gastronome, naturaliste, agronome, ingénieur

\footnotetext{
7 No por casualidad esta reactualización coincidió con la moda de las novelas de filibusteros y de la literatura «marítima» de las que el propio t'Serstevens era productor: ver, por ejemplo, sus novelas Les Corsaires du roí (1930), L'Or du 'Cristobal' (1936) o Ceux de la mer (1937).

${ }^{8}$ Reedición que hizo Phébus en 1993 de Nouveau voyage aux isles de l’Amérique.
} 
militaire, expert en l'art de traiter la canne à sucre, espion, administrateur, historien, sociologue, pêcheur, jardinier, explorateur, ethnographe, selon les nécessités du moment (Le Bris, in Labat, 1722d: 10).

Además de las múltiples habilidades demostradas durante su etapa caribeña y las portentosas hazañas que de él se cuentan -en las que no falta una parte de leyenda (Rubiales, 2011: 345-346)-, Labat fue profesor de Filosofía, Matemáticas y Teología en Nancy y en París y participó en la guerra de Flandes como capellán militar, antes de embarcar hacia las islas en 1693. A su vuelta de América, tras su breve periplo español, viajó durante varios años (de 1706 a 1716) por Italia y Francia hasta que, perdida la esperanza de poder regresar a las islas, se retiró en el convento de los Jacobinos9 de la calle Saint-Honoré de París donde había hecho profesión en 1685 y donde habría de componer su obra, siendo nombrado bibliotecario en 1721 (Chatillon, 1979: 7).

Se dice que no pasaba desapercibido allá por donde iba y que la burguesía criolla y las autoridades locales ejercieron ante Luis XIV todo el poder del que disponían para evitar que el religioso regresara a las islas como era su intención cuando partió de ellas en 1705: en 1708, el rey «l'exila au couvent de Toul et lui interdit toute correspondance avec les Antilles» (Rennard, 1926: 27). Las razones que impidieron la vuelta de Labat a las colonias han intrigado a casi todos sus biógrafos. Lafcadio Hearn sugiere que su carácter, su «franqueza cínica» y las rivalidades que se granjeó en las islas podrían haber sido el motivo de tal prohibición (Hearn, 1890: 73). Por su parte Joseph Rennard descarta la acción de los jesuitas contra Labat, hipótesis barajada por algunos, y cita un informe del Gobernador y del Intendente de la Martinica de 1708 en el que aseguraban que: "Quoique le P. Labat soit un homme de mérite, son esprit est si vif que c'est un bien qu'il ne revienne plus dans les colonies, où les génies trop intrigants ne conviennent nullement» (apud Rennard, 1926: 26) ${ }^{10}$.

Por otra parte, la modestia no estaba entre sus virtudes ni la prudencia en sus juicios sobre los demás, en particular si estos eran negros, criollos, mujeres o médicos. Así, su perspicacia, su malicia y una ironía a veces cáustica lo convirtieron en una pluma temida por aquellos que constituyeron el blanco de sus críticas. En este sentido, Hearn añora en Labat «algún atisbo»

9 Término por el que se conocen también en Francia a los religiosos de la orden de los Dominicos o Predicadores, debido al emplazamiento de uno de sus primeros conventos de París en el antiguo hospicio de Saint-Jacques.

10 En una nota biográfica más reciente, se puede leer: «Cabaleur impénitent, il embarque en 1705 pour la France, à l’insu du gouverneur général Machault, afin de dénoncer ses démêlés avec les religieux placés sous sa responsabilité. En 1708, il apprend, à La Rochelle, que Pontchartrain s'oppose à son retour aux îles. Revenu à Paris en 1709, et exilé à Toul, il se rebelle, et part pour l'Italie. Rentré en grâce en 1716, il regagne le couvent de la rue SaintHonoré où, de 1727 à son décès, il exerce les fonctions d'agent du Maître général de l'Ordre» (Élisabeth, France Archives https://francearchives.fr/commemo/recueil-2013/39388). 
de la bondad del Padre du Tertre ${ }^{11}$ y de su compasión por la condición de los negros esclavos. Nada de esto en Labat quien, interesado únicamente por hacerles abjurar de la superstición, utilizando, si era necesario, la manière forte, «ne paraît pas éprouver la moindre commisération pour leur triste sort» (Hearn, 1890: 85). Por su parte, t'Serstevens no encuentra «une seule parole de bonté» en su libro sobre España e Italia,

[...] en revanche, les sarcasmes et les brocards pleuvent comme averses de novembre. Les malheurs d'autrui le remplissent d'une joie de cannibale. Il ne les provoque jamais, au moins ouvertement, mais il s'en délecte à grand bruit et nous en fait part avec prolixité (in Labat, 173ob: 19).

Es preciso tener en cuenta estas disposiciones personales del autor, en particular su humor punzante y socarrón ${ }^{12}$, a la hora de interpretar en su justa medida su percepción de España y de los españoles en la obra que aquí nos ocupa ya que, al margen de un componente chauvinista mal disimulado, de ella se desprende un egocentrismo propiamente «labatiano» que lo lleva con frecuencia a la autocelebración, incluso a la fanfarronería, en detrimento de sus anfitriones ${ }^{13}$. Habría que añadir en este sentido que, durante su experiencia caribeña, Labat tomó parte activa en la defensa de los intereses territoriales de Francia frente a España e Inglaterra y que los que ahora, en un contexto de paz franco-española, eran sus anfitriones, habían sido sus enemigos poco tiempo antes.

Si la trayectoria y las disposiciones personales de Labat van a determinar en cierta medida su relación con el país y sus habitantes, la propia naturaleza del viaje español pudo igualmente incidir en la actitud del viajero hacia la realidad local, como se verá en las líneas que siguen.

\section{El relato de un contratiempo}

Además de los numerosos errores señalados por Irene Aguilà (2007) en la traducción que hizo García Mercadal del texto de Labat, hay uno bastante sorprendente, ya que afecta a la propia coherencia entre texto y paratexto: en la «Nota del traductor» se dice sobre el viajero que «las dificultades para dirigirse a Italia por el mediodía de Francia le decidieron a cruzar España, y ese fue el motivo de que pudiera más tarde redactar su Viaje por España, aprovechando las notas que entonces recogiera» (in Labat, 1730d:

${ }^{11}$ Jean-Baptiste du Tertre (1610-1687), religioso dominico que conoció una etapa anterior de la colonización francesa de América y escribió la primera relación importante sobre las Antillas francesas, Histoire générale des Antilles habitées par les François (1667-1671).

12 Un documentalista de la Biblioteca Nacional de Francia -que casualmente era dominico y había hecho profesión, como Labat, en el convento de la calle Saint-Honoré- nos confesó que, en el seminario, durante el recreo, leían al padre Labat «pour rire».

${ }_{13}$ El autor de una breve biografía de Labat afirmaba en 1854: «quelques'uns de ses critiques l'ont qualifié de bavard, de crédule, de vaniteux; ce n'est pas sans raison» (A. de L., 1854: 334). 
44). Sin embargo, el propio autor cuenta cómo, ante la imposibilidad de emprender la vía mediterránea hasta Marsella por el bloqueo de Gibraltar y la inconveniencia de cruzar España por el mal estado de los caminos y los frecuentes pillajes (Labat, 1730a: 52), acabó tomando la vía atlántica a bordo del Constant, hasta La Rochelle ${ }^{14}$.

Así pues, el título que Labat dio a su periplo español parece cuando menos abusivo si se compara con el territorio recorrido y con la propia naturaleza del viaje que, como han observado los estudiosos del texto, más que de un viaje en el sentido clásico del término, se trata «[d'un] un séjour forcé» (Sarrailh, 1963: 169) o "d'un séjour involontaire» (Tamarit, 2006). En efecto, aunque compuesto bastantes años después del viaje ${ }^{15}$, el relato muestra con gran viveza a un Labat contrariado por las circunstancias e impaciente por proseguir su camino ya que, «outre la dépense que j'étois obligé de faire, mon retardement nuisoit infiniment aux affaires pour lesquelles j'étois envoyé» (Labat, 1730a: 413). Esto no le impidió, más bien le impulsó a buscar distracciones y ocupaciones con las que matar el tiempo: «Pour passer mon tems avec moins d'ennui, je me mis à apprendre la Langue Espagnole, \& pour tirer quelque profit de mon étude, je cherchai des Livres qui m’instruisissent de l'origine de la Ville de Cadis» (Labat, 1730a: 52).

Después de recorrer la ciudad en todos los sentidos -lo que no le debió llevar mucho tiempo dadas las reducidas dimensiones de la misma-, de observar su estructura y su arquitectura y de investigar sobre su historia, Labat no tardó en buscar, más allá de las Puertas de Tierra, algún motivo de distracción, «[...] parce que je commençois à m'ennuyer très-fort à Cadis» (Labat, 1730a: 301). Por esta razón, no dudó en visitar «lo que había que ver» en los alrededores: el bloqueo de Gibraltar (pasando por Conil, Vejer, Tarifa, Algeciras) y la que fuera la capital oficial del comercio transatlántico hasta 1717, Sevilla (pasando por El Puerto de Santa María, Jerez, Sanlúcar y Castilleja). Parece evidente que, después de doce años de intensa actividad en las Antillas, el confinamiento forzoso en una ciudad-isla en la que ninguna misión particular lo retenía no siempre fue bien llevado por el inquieto fraile. En contrapartida, el ocio obligado, unido a su carácter emprendedor y a su curiosidad natural, lo llevó a indagar en conventos y capillas, a recorrer baluartes y murallas, a curiosear en casas y cuevas. Así por ejemplo, de su inútil desplazamiento para ver «de cerca» las llamadas columnas de Hércules, Labat escribía:

[...] il n'y a ni inscriptions, ni bas reliefs, ni restes de figures quelconques. En un mot, rien qui meritat nôtre attention ni qui recompensat la moindre partie de la peine que nous avions prise pour les aller voir de près. Car je

14 En el índice se indica claramente: «Chap. XI: L'Auteur s'embarque sur un Vaisseau du Roy. Son voyage jusqu'à la Rochelle, 415-420».

${ }^{15}$ En el capítulo V, Labat declara: «[...] dans le moment que j’écris en l'an 1725 depuis la venue du Messie» (Labat, 1730a: 112). 
les avois vû plus d'une fois du grand chemin, où j'avois passé, \& je devois me contenter. Mais que ne fait-on pas quand on est curieux, \& aussi désœuvré que je l'étois alors (Labat, 1730a: 383).

Las limitaciones espacio-temporales y la ausencia de motivación del viaje no constituyeron condiciones propicias para la recopilación de notas a partir de las cuales componer un relato. De ahí, probablemente, la inclusión de dos amplísimas referencias eruditas sobre la historia de Cádiz ${ }^{16}$, que ocupan sendos capítulos (casi el 40\% de la extensión total del texto) y que, con el pretexto documental, completan un volumen que, de otra manera, habría resultado muy poco consistente para una publicación ${ }^{17}$. Hay que precisar, no obstante, que estas referencias no se limitan a la traducción literal de las fuentes, antes bien el narrador las resume, las parafrasea y las glosa sin privarse de evaluar, corregir o precisar la información de los eruditos españoles y manifestando en todo momento su posición de autoridad sobre la misma $^{18}$. En cualquier caso, consciente del exceso de erudición, el narrador se hacía cómplice del lector que pudiera juzgar aburridos dichos pasajes, con la siguiente disculpa retórica: "Nous voilà enfin au bout de ces faits Chronologiques. Je crains qu'ils n'ennuyent les Lecteurs. Mais je les prie de considerer qu'il m'ont ennuyé le premier, \& très fort» (Labat, 1730a: 135).

Por otra parte, si el aburrimiento del viajero se presenta como el motor de las excursiones que lo llevan hasta Sevilla y Gibraltar, el relato de las mismas viene en cierta medida a soslayar el aburrimiento del lector, aportando la dosis de acción que el público de la época esperaba encontrar en los relatos de viaje. No hay que olvidar que, con su relación americana, Labat se había convertido en un maestro del género y dominaba a la perfección las técnicas y los tópicos de la aventura: el desplazamiento, las peripecias, el suspense, la sorpresa..., incluso la búsqueda de un supuesto tesoro que los lugareños creían (o quisieron hacerle creer) que existía en el castillo de Don Julián (Labat, 1730a: 325-727).

\footnotetext{
${ }^{16}$ En el capítulo IV: «Description de l'Isle \& de la Ville de Cadis par Jean-Baptiste Suarès de Salazar Chapelain de la Cathédrale de cette Ville» a partir de Grandezas y antigüedades de la isla y ciudad de Cádiz (Cádiz, 1610) (Labat, 1730a: 51-91) y en el capítulo V: «Description plus particulière de l'Isle \& de la Ville de Cadis», a partir de una obra de Fray Gerónimo de la Concepción Emporio de el Orbe, Cádiz Ilustrada (Ámsterdam, 1690) (Labat, 1730a: 91-222).

${ }^{17}$ La misma función parecen cumplir otros fragmentos textuales heterogéneos con los que el autor engrosa el volumen, como el capítulo III, dedicado al estado de las misiones en Filipinas, y el capítulo XI, en el que reproduce en español y en francés la Bula de la Cruzada y la relación detallada del gasto mensual del barco en el que regresa a Francia.

${ }^{18}$ Para ello, el transcriptor utiliza fórmulas como: «Je ne croi pas que l'Auteur veüille nous obliger de croire, que [...]» (1730a: 64); «Voici quelque chose de plus bien réel que tout ce que nôtre Auteur nous a rapporté jusqu'à présent [...]» (77); «Le P. Jerôme prétend que [...]» (113); «Je ne vois pas par quel droit le P. Jerôme change ainsi les noms [...]» (113), etc.
} 
De manera general, en el relato de Labat pueden distinguirse tres grandes campos de interés, si atendemos al lugar que ocupan en las descripciones como en las digresiones, incluso en las anécdotas: en primer lugar, la arquitectura militar y defensiva, con la que estaba muy familiarizado por su propia labor en la fortificación y defensa de las islas. De hecho, el punto de vista que domina en su descripción de las ciudades españolas es el del ingeniero-estratega, el mismo que había dominado su observación de las islas del Caribe ${ }^{19}$. En segundo lugar, Labat se detiene en las instituciones y edificios religiosos, en cuya descripción no escatima detalles sobre la estructura, la ornamentación, los materiales, la factura y, en general, la calidad y la belleza (o la fealdad) de los mismos. Por último, las cuestiones materiales, que se plasman en los numerosos comentarios sobre el comercio y el dinero así como sobre los usos sociales, la vestimenta, el mobiliario y, por supuesto, la gastronomía, ya que el religioso era de buen comer y mejor beber.

Si el relato de Labat no responde a un proyecto de relación metódica ni sistemática de los lugares visitados (y, en cierto sentido, soportados), durante su escala, el conjunto traduce un esfuerzo por dotar de contenido un «viaje por España» que justificara su inclusión en una misma obra, junto a los otros siete que el autor dedica a sus viajes por Italia, durante los cuales tuvo tiempo de vivir numerosas experiencias y de engrosar su cuaderno de notas. Precisamente, ese desajuste entre las limitaciones del contenido y la enjundia que le otorga el título "Voyages en Espagne» es indicativo del interés del autor por la publicación de un testimonio sobre España en esos momentos. El éxito de la Relation du voyage d'Espagne de Mme d'Aulnoy -Foulché-Delbosc señala diez reediciones de 1691 a 1716 (1896: 85-87)- y una relativa escasez de testimonios sobre España en las primeras décadas del siglo XVIII podrían haber constituido alicientes para componer y publicar el relato de su periplo español. Sin olvidar la publicación, en 1721, de Lettres persanes de Montesquieu que contiene la famosa carta $\mathrm{n}^{\circ} \mathrm{XXVIII}$ «d'un François qui est en Espagne». A esto se añade que, para Labat, como para muchos de sus contemporáneos, España se presenta en la época «como una tierra de oportunidades, facilitadas por el escaso apego de los españoles al trabajo, lo que dejaba campo libre a sus compatriotas» (Salas, 2003: 143). Por ello, como buen emprendedor y buen patriota, no quiso quizá desaprovechar la ocasión de instruir a sus contemporáneos sobre aspectos del país vecino que podrían serles de utilidad en sus futuras aventuras españolas y, más concretamente, gaditanas: la información sobre las distancias, los recursos naturales de la comarca, el volumen y el funcionamiento del comercio, las trabas impuestas a los extranjeros, el contrabando, el coste de la

19 «Il ne met pas le pied dans une île sans l'examiner au point de vue stratégique; il compte les batteries et les cannons qui défendent l'entrée des ports, il sonde la puissance et les points faibles des fortifications, examine les moyens d'en assurer la défense ou de s'en emparer» (Rennard, 1926: 18). 
vida $^{20}$, etc. se presenta a menudo bajo la forma explícita o implícita de consejos, advertencias o recomendaciones -a veces señalados en el margen de la página con fórmulas como «Avis de l'Auteur au Lecteur» (Labat, 1730a: 271) - sobre cómo conducirse con los españoles para no verse perjudicado en su trato con ellos ${ }^{21}$. Esto era de especial importancia,

car il faut savoir qu'il n'est permis à qui que ce soit de trafiquer aux Indes Espagnoles qu'aux seuls Espagnols naturels de sorte que tous les autres Marchands passent par leurs mains, se servent d'eux, \& se rapportent à leur bonne foi pour la perte \& le profit qui s'est trouvé sur leurs Marchandises (Labat, 1730a: 293).

Por último, si, desde el punto de vista del viaje, Cádiz constituye una escala en el itinerario del viajero, que lo lleva del Caribe a Italia, desde el punto de vista del género, el relato de Labat sobre España constituye una bisagra entre dos tradiciones de la literatura viática en las que se inscribe su obra: la relación americana y el itinerario del Grand Tour, del que Italia formaba parte. Es preciso señalar además que, desde la estancia de Labat en Cádiz en 1705-1706 hasta su retiro en el convento de su orden en París, el estatus de la ciudad en las relaciones de viaje había cambiado considerablemente:

La grande fortune de Cadix, héritière du trafic américain après le transfert en 1717 de la Casa de Contratación, jadis installée à Séville, imposa cette ville au programme du voyage en Espagne et, désormais, la description souvent très détaillée et précise de Cadix figure à la table de toute relation importante (Bennassar, 1998: XIII).

\section{Labat en Cádiz: entre franceses...}

Cuando Labat llega a Cádiz, el 10 de octubre de 1705, España estaba inmersa en la guerra de sucesión (1702-1713) y la sociedad española dividida entre los partidarios del «archiduque» y los defensores del «nieto del rey de Francia» que, de hecho, reinaba desde 1700 y por el que Cádiz realizaba un gran esfuerzo de guerra en esos años (Bustos, 1984). Por lo tanto, el viajero desembarcó en un territorio oficialmente amigo aunque, según se desprende de su relato, el «apego» a Felipe V no era un sentimiento generalizado entre la población gaditana.

\footnotetext{
20 «[...] il fait cher vivre à Cadis; \& encore plus cher mourir. C'est pourquoi je conseille à ceux qui liront ces Memoires de ne pas demeurer long-tems à Cadis, à moins qu'ils ne trouvent à y gagner beaucoup d'argent ; de n'y être point malades, parce que les Medecins sont ignorants, \& chers comme partout ailleurs, \& sur tout de n'y point mourir, à cause que les dépenses des enterrements sont excessives» (Labat, 1730a: 271-272).

${ }^{21}$ «Au reste, ceux qui ont quelque séjour à faire à Cadis, doivent bien prendre garde de ne pas donner deux fois de suite à ces Quêteurs; car il n'en faut pas davantage pour se voir obligé à une rente perpetuelle, dont on ne pourroit plus se dispenser sans s'attirer de mauvaises affaires, ou au moins de mauvais discours» (Labat, 1730a: 280).
} 
Por su interés estratégico y comercial, la ciudad de Cádiz se presenta como una plaza codiciada por las potencias extranjeras, que vivía continuamente con el temor de un asalto, como los que ya había sufrido en el pasado y aún permanecían en la memoria de sus habitantes. Por su parte, el narrador fantaseaba con un hipotético asalto francés a la ciudad, lo que consideraba factible pero poco inteligente dado que «ce seroit [...] détruire un commerce avantageux à la France, \& empêcher le débouchement de ses denrées \& de ses Manufactures» (Labat, 1730a: 294), hasta el punto de que, según él, Cádiz debía su conservación al puro interés comercial de los franceses.

Como francés que no hablaba español -a diferencia de otros religiosos que visitaron España por la misma época, como François Bertaut (16211701) o Jean de Vayrac (1664-1734)-22, Labat se desenvolvió sobre todo en los círculos franceses y «afrancesados»: nada más llegar, e impelido por el poco acomodo que encuentra en el convento de su orden, donde se siente ninguneado y alojado de manera tosca, Labat entra en contacto con la colonia francesa de Cádiz, «corps national»o «Nation française» 23 , a la que alude en su evocación de los lugares de sociabilidad de dicha colonia, como la hospedería «Le Soleil» o la cofradía de San Luis de Francia -sita en el convento de San Francisco-, la cual «[...] comprend tous les Négociants François établis à Cadis, \& tous ceux qui y viennent pour le commerce. Elle attire, chés les Cordeliers, toutes les sepultures, les services, \& generalement toutes les cérémonies que la Nation Françoise fait faire» (Labat, 1730a: 275). ${ }^{24}$

Pero los grandes comerciantes y hombres de negocios que constituían la «Nation française» no son los únicos franceses que aparecen en el relato. Al número considerable de compatriotas evocados hay que añadir la variedad de sus orígenes regionales y de sus perfiles profesionales (militares, religiosos, tenderos, pescadores, agricultores, vendedores ambulantes, hosteleros, etc.) y, sobre todo, la diversidad de posiciones que ocupaban en

\footnotetext{
${ }^{22}$ Autores, respectivamente, de Journal du voyage en Espagne (1669) y État présent de l’Espagne (1718).

23 «Les Français adonnés au commerce étaient groupés à Cadix en un 'corps de nation', c'est-à-dire une sorte d'association ou de chambre représentant les intérêts du commerce national dans la ville. Présidé par le consul de France, ce 'corps de nation', ou plus simplement la 'Nation française', se réunissait périodiquement en assemblées où se discutaient les affaires de la collectivité et élisait deux députés chargés de les suivre et de gérer un budget alimenté par certains droits et des cotisations. Cette caisse était destinée à aider les compatriotes en difficulté, à entretenir la chapelle française, à organiser les cérémonies et célébrations officielles, etc.» (Ozanam, 1968: 266).

24 Labat relata con mucho detalle el entierro, en dicho convento, del Señor de Monsegur, un compatriota muerto en Cádiz, al poco de llegar de la Martinica, a causa, cuenta el religioso con sarcasmo, de la «afortunada» colaboración entre los médicos españoles y los cirujanos franceses: «M. de Monsegur tomba malade six ou sept jours après qu’il fut arrivé. Les Chirurgiens François et les Médecins Espagnols qui le virent travaillerent si heureusement sur lui qu'ils l'expedierent le cinquième jour de sa maladie» (Labat, 1730a: 268).
} 
el espacio social que iba del «extranjero» (la «Nation française» era, por definición, extranjera) al «natural».

En el extremo más alejado de los naturales del país aparecen los transeúntes, que compartían un mismo «esprit de retour», pero que podían representar trayectorias muy diversas, asociadas a estancias más o menos largas, más o menos frecuentes. Es el caso del propio autor y del religioso trinitario Dominique Busnot, que se alojaba en la misma hospedería. Ambos eran transeúntes en la doble acepción del término, es decir se trata de extranjeros que se encontraban en Cádiz de manera provisional y que estaban de paso hacia otro lugar, el reino de Marruecos en el caso de Busnot ${ }^{25}$. La presencia de un considerable número de transeúntes y de otras categorías de franceses apegados a su lengua y a su nación explica la existencia de religiosos franceses que confesaban a los miembros de la comunidad gala. Es el caso del Padre Diego, religioso mercedario «[qui] confesoit la plus grande partie des François de Cadis, \& surtout les Maloüins qui y commerçoient» y que confiaban mucho en él «tant à cause de ses bonnes qualités, que parce qu'il étoit leur compatriote» (Labat, 1730a: 276). El propio Labat obtuvo el permiso del obispo para confesar a algunos franceses «qui étoient à Cadis, qui m'en avoient prié» (Labat, 1730a: 260) y sugirió a los religiosos de su orden que trajeran a dominicos franceses para tales fines, siguiendo el ejemplo de los jesuitas, que tenían confesores y directores espirituales en todas las lenguas (Labat, 1730a: 276).

En general, Labat menciona un cierto número de franceses que, como otros extranjeros, «ne manquent gueres de faire tous les trois ans un voyage dans leur Paiis, \& d'y porter trois ou quatre cens Piastres, \& souvent davantage (Labat, 1730a: 286) lo que muestra al mismo tiempo un asentamiento durable y un «esprit de retour». De un comerciante marsellés llamado Achard, Labat precisa «[qu'il] étoit établi à Cadis, \& [qu'il] y faisoit un négoce considerable» (Labat, 1730a: 2); o de los marineros que lo conducen a Sevilla por el Guadalquivir: «Nos Matelots que nous avions crû Espagnols, étoient des Provençaux de Martegues, il avoit bien des années qu'ils étoient dans ce Païs-là» (Labat, 1730a: 358). Puede hablarse en estos casos de «avecindados», es decir, de franceses asentados en la vida española de manera durable aunque, desde el punto de vista jurídico, este estatus no se formalizó hasta 1716 y suponía la renuncia a la protección del cónsul francés y el juramento a la corona española (Bartolomei, 2011: 128).

\footnotetext{
25 Dominique Busnot (1647-1714) se encontraba efectivamente en Cádiz durante la estancia de Labat, de vuelta de una misión fracasada para liberar a esclavos cristianos en Marruecos, de lo cual dio cuenta en Histoire du règne de Mouley Ismael, roi de Maroc, Fez, Tafilet, Souz, etc..., de la cruelle persécution que souffrent les esclaves chrétiens dans ses états avec le récit de trois voyages à Miquenez et Ceuta pour leur rédemption et plusieurs entretiens sur la tradition de l'Église pour leur soulagement (1714).
} 
Un grado más en la cercanía a los autóctonos lo constituyen los franceses a los que Labat denomina «españolizados», término que no hace referencia a un estatus jurídico particular sino a conjunto de signos visibles que muestran, de alguna manera, la disolución de «lo francés» en «lo español». Es el caso de la Señora de la Rosa, criolla francesa de la Martinica a la que Labat había conocido de niña en la isla y que, en ese momento, casada con el Marqués de la Rosa, casi había olvidado su lengua y sus costumbres, hasta el punto de que «elle étoit devenuë Espagnole depuis la tête jusqu'aux pieds. A peine pouvoit-elle dire une phrase en François, sans y mêler de l'Espagnol» (Labat, 1730a: 9). En Sevilla, Labat visita a un «Négociant François Espagnolisé» lo que se muestra en signos externos como la indumentaria (lleva gafas y golilla) y en la manera «gravement civile» de recibirlo (Labat, 1730a: 362). De su hospedera en Cádiz, dice que «[elle] étoit née à Cadiz, de pere et mere François, mais elle n'en étoit pas moins Espagnole» (Labat, 1730a: 396-397).

Sería difícil determinar, salvo en los casos en los que la indicación de la filiación permite adscribirlos a una categoría jurídica determinada -como los hijos de franceses nacidos en España (jenízaros) ${ }^{26}$ - a qué otras categorías pertenecían los franceses, españolizados o no, mencionados por Labat, de entre las que señala Arnaud Bartolomei, a saber, avecindados, naturalizados, naturalizados con licencia y jenízaros (Bartolomei, 2011: 127). Sea como fuere, sin mencionarlas, o haciéndolo de manera indefinida -como con la categoría «españolizado»-, Labat hace referencia a una serie de trayectorias que socavan el carácter dicotómico y excluyente de la oposición francés / español, lo que coincide con la constatación de Tamar Herzog sobre la construcción de las categorías de «naturales» y «extranjeros» en el mundo hispánico:

[...] aunque hubo naturales y extranjeros, más que condiciones concretas, se trataba de dos extremos de un continuum que iba de los completamente (y claramente) naturales a los completamente (y claramente) extranjeros, pasando por una variedad de situaciones intermedias que indicaban la posibilidad, por ejemplo, de que uno fuera más extranjero que natural, o más natural que extranjero. $\mathrm{O}$, dicho de otro modo, no se trataba solo de la pregunta de quién era natural y quién extranjero, sino hasta qué grado y en qué manera (Herzog, 2011: 27).

Por otra parte, aunque solo fuera por la importancia del elemento galo y la existencia de un cierto «mestizaje» franco-español en la sociedad gaditana de la época, Cádiz difícilmente podría aparecer ante los ojos del viajero como un lugar exótico, en el sentido en el que aquí lo entendemos. De hecho, en el prólogo, el autor insiste en que todo lo que cuenta en su

${ }^{26}$ Se entiende que tanto la categoría de "avecindado" anteriormente evocada, como la de "jenízaro", son comunes al conjunto de los extranjeros, no exclusivas de los franceses. 
relato sobre España e Italia es de la más absoluta veracidad ya que sería una torpeza pretender engañar a un público al que considera totalmente familiarizado con los lugares en cuestión:

[...] ce ne sont point des terres nouvellement découvertes dans la description desquelles un Ecrivain pourroit s'égayer au dépens de la vérité, on connoît celles-ci, on les frequente depuis bien des siècles, j'aurois contre moi une nuée de témoins, si je m'écartois tant soit peu de mon devoir \& de la fidélité que je dois au Public (Labat, 1730a: v).

Esta estrategia retórica para comprometer al lector en un cierto régimen de lectura y hacerle aceptar el «pacto de veracidad» se apoya en un argumento que, en lo relativo a la presencia francesa en la bahía de Cádiz, responde a una realidad sociológica documentada 27 . Con todo, si bien esta realidad factual tiene su importancia para contextualizar la experiencia del viajero al contacto con el territorio extranjero, no es por sí sola suficiente para explicar su relación con el mismo. De ser así, el discurso sobre «[les] terres nouvellement découvertes», que fueron objeto de su relato americano, habría estado necesariamente marcado por el exotismo. Sin embargo, esto no es así. Muy al contrario, la lógica colonial que subyace en la experiencia caribeña del autor determina un discurso que supone tanto su voluntad de conocimiento de la realidad en cuestión como su implicación práctica en la misma, operaciones ajenas a la actitud exótica.

\section{5. ...y españoles}

A pesar de la declaración de intenciones del autor en el prólogo de los Voyages afirmando haberse centrado más «sur [les] beaux endroits que sur [les] défauts» (Labat, 1730a: iii) de italianos y españoles, no puede decirse

${ }_{27}$ Cierto es que la mayoría de los estudios sobre la comunidad francesa en Cádiz se centran en la segunda mitad del siglo (véase, por ejemplo, Ozanam, 1968; Bartolomei, 2011), época en la que la comarca conoce su apogeo, la comunidad extranjera aumenta y los censos se perfeccionan. Pero estos estudios hacen referencia también, en su mayoría, a la progresión de la población desde principios de siglo, aunque de forma estimativa dada la precariedad de los censos y los obstáculos inherentes a la definición de «extranjero» durante todo el siglo XVIII. No obstante, si Pierre Villars afirmaba que había más de setenta mil franceses en todo el territorio español a finales del siglo XVII (Villars, 1733: 6), en tiempos del viaje de Labat «aseguraban»: "qu'il y avoit dans la seule Andalousie plus de vingt mille François des Provinces d'Auvergne, de la Marche, du Limousin, \& des environs de la Garonne, dont le métier étoit de porter de l'eau dans les maisons, de vendre dans les ruës du charbon, de l'huile, du vinaigre, de servir dans les Hôtelleries, de labourer les terres, \& faire les moissons, \& d'y travailler les vignes» (Labat, 1730a: 286). En cuanto a Cádiz, Jacques Mirasol, cónsul de Francia de 1701 a 1715, «indique [en 1705] qu'environ trois cents Français pouvaient être armés afin de constituer une milice pour défendre la ville» (Mézin, 2016: http://books.openedition.org/pan/464). 
que derrochara halagos ni que se privara de ridiculizar el «carácter» o ciertas costumbres de los locales ${ }^{28}$. Ahora bien, de ahí a concluir que su discurso traduce «[une] haine enracinée de l'Espagnol» (t'Serstevens, in Labat, 1730b: 26) parece, cuando menos, exagerado. Cierto es que la experiencia caribeña había constituido, para un patriota como él, una escuela de hostilidad hacia lo hispánico, cuyo poderío en América era el blanco de las potencias europeas. Pero no hay que olvidar que, desde finales del siglo XVI, el rango de España en Europa había ido decreciendo. Pierre Villars, que visitó España por primera vez en 1668 y fue embajador en Madrid en varias ocasiones, empezaba así sus Mémoires de la cour d'Espagne de 1679 a 1681:

L'idée que ces mémoires pourront donner de l'État et du Gouvernement présent de l'Espagne aura sans doute peu de rapport à celle que la puissance et la politique des Espagnols avoient autrefois répandue dans le monde; mais personne n'ignore que, depuis le commencement de ce siècle, l'une et l'autre ont toujours été en diminuant. Ce changement est devenu si grand dans ces derniers temps, que d'une année à l'autre on auroit pu s'en apercevoir (Villars, 1733: 1).

Paralelamente, desde las primeras derrotas de la armada española hacia mediados del XVII, el orgullo francés había ido en aumento y, aunque la base de los estereotipos que se habían forjado en siglos anteriores sobre España se mantenía, las fisuras en el prestigio de la nación permitieron que algunos de ellos se dotaran de valores distintos: lo que antes se percibía como temible ahora se miraba con desdén o con ironía (Dubost, 1999: 672).

La gravedad y el orgullo, por ejemplo, seguían considerándose como constitutivos del carácter nacional visto desde el exterior, con la diferencia de que ahora se presentaban como gestos huecos y se expresaban con frecuencia a través del motivo de lo que Anna Raventós denomina la «dignidad desplazada» o «el orgullo fuera de lugar» (2007: 453). Para Labat, en efecto, la dignidad y el orgullo de los españoles se reducía a un afán de aparentar y se alimentaba de los vestigios del pasado, lo que le lleva a burlarse, por ejemplo, del interés de los lugareños por hacerle creer que ciertas construcciones eran mucho más antiguas, es decir, más nobles, de lo que en realidad eran. Así, de la antigua catedral de Cádiz, el narrador afirma:

Quelques ignorants nous vouloient faire croire, que c'étoit la plus ancienne Eglise du monde, \& qu'elle avoit servi de Temple à Hercule. Heureusement j'avois lû les descriptions de Cadis par le Chanoine \& par le P. Jerôme, ces Livres m'empêcherent d'être trompé (Labat, 1730a: 260).

\footnotetext{
${ }^{28}$ Aunque el periplo español de Labat tuvo una extensión geográfica muy reducida, los enunciados sobre el carácter local tienen, en la mayoría de los casos, un valor de generalización nacional. Rara vez, para denominar a los autóctonos, Labat usa el término «gaditano», o «sevillano», y, aún menos «andaluz», que carecía de entidad en la época.
} 
O del acueducto que llevaba el agua desde la Sierra de las Cabras a Cádiz:

C'étoit un grand ouvrage, le peu que nous en vîmes portoit les marques d'une très-haute antiquité; mais je ne voudrois pas assurer qu'il le fut autant que les Espagnols le disent. J'admire en cela leur modestie. Ils auroient pû dire qu'il étoit fait avant le Déluge. Qui le leur auroit contesté? (Labat, 1730a: 355).

El apego al pasado se muestra asimismo en el empecinamiento hispánico por seguir las reglas antiguas en las realizaciones modernas a pesar de su demostrada ineficacia. A propósito de los muros de las baterías de cañones, por ejemplo, Labat pone en boca de un tal Renau, ingeniero de la marina francesa, que estaba en Cádiz como ingeniero general del rey, las razones por las cuales dichos muros se construían de manera precaria. Una de las razones aducidas era el trabajo generado por las continuas reparaciones, del que vivía mucha gente; la otra, que «[...] en Espagne plus qu'en aucun lieu du monde, il falloit suivre les vieilles regles quelques mauvaises qu'elles fusent, sur tout dans les commencements d'une nouvelle Monarchie» (Labat, 1730a: 292).

Junto a la gravedad y el orgullo, la pereza aparece de manera recurrente en el discurso de Labat como resorte para explicar el atraso del país así como los robos, el fraude, la mendicidad, la miseria y otras lacras que relaciona con ella. El relato contiene numerosos comentarios que, de manera implícita o explícita, relacionan las costumbres locales con la pereza y la indolencia, encontrando en ellas la causa de que el latín se utilizara poco, de que las misas se despacharan en tiempo excepcionalmente corto o de que los religiosos, en vez de pasear después de comer, durmieran la siesta. Labat describe así a los españoles como gente poco dada al esfuerzo y poco eficiente, razón por la cual, como afirmaba también Villars, España debía recurrir a los extranjeros para que realizaran todo aquello que ellos «ne peuvent ou ne veulent point faire» (Villars, 1733: 6). De esta manera, el orgullo infundado, el rechazo a la innovación y la indolencia con los que se representa a los españoles en la época podían constituir, para los franceses, atractivos suplementarios a las potencialidades que ofrecía España para el comercio.

Por otra parte, como observa Tamarit, no es raro que los juicios positivos de Labat sobre los españoles o sobre sus costumbres vayan acompañados de un contrapunto negativo (Tamarit, 2006: 275) : por medio de una adversativa, de una condicional, de una concesiva y, sobre todo, a través de la ironía, Labat cuestiona, rebaja y hasta anula un enunciado inicialmente, o aparentemente, positivo: "Le forment vient à merveille dans tout le Païs, il est gros, dur, pesant, d'une belle couleur, \& feroit le plus beau pain du monde s'il étoit bien travaillé» (Labat, 1730a: 316). Incluso cuando la valoración del resultado es «excelente» (como el vino, que casi siempre lo es), 
ello es, en muchos casos, a pesar de los medios que lo hacían posible: «Le vin est excellent malgré le peu de culture qu'ils font aux vignes, \& leur mauvaise maniere de [le] faire» (Labat, 1730a: 316).

Por lo demás, las calles sin asfaltar, los caminos impracticables, las tierras incultas, los pueblos deshabitados y en ruina que Labat evoca en su relato no contribuyen a dar una imagen muy positiva de la España de la época. Si exceptuamos la ciudad de Cádiz, centro indiscutible de la actividad económica y comercial, las tierras que Labat visita al Sur aparecen en un estado ruinoso y despoblado debido, según explica, a la expulsión de los últimos moriscos y a la propia atracción de la capital sobre las poblaciones aledañas. En cuanto al Norte, el panorama era el de una comarca, otrora pujante gracias al papel de Sevilla pero que se resentía visiblemente a causa de la competencia gaditana.

Ya se han mencionado las largas referencias librescas con las que Labat, con el pretexto de instruir, parece querer engrosar el volumen, aunque fuera a costa del aburrimiento del lector y del suyo propio. Pero las coincidencias de algunos detalles con los que encontramos en otros relatos de la época, hacen suponer que el autor recurrió a otras fuentes, no declaradas, que probablemente le sirvieron para completar ciertas informaciones (ver infra, notas 29 y 31) o para interpretar sus observaciones en un determinado sentido. De ahí, en parte, el recurso a ciertos tópicos -la gravedad, el orgullo, la pereza, la ignorancia-, que se repetían no solo en las relaciones de los viajeros sino también en los textos que recogían el saber enciclopédico de la época sobre España (Bolufer, 2003; Testino-Zafiropoulos, 2008).

Sea como fuere, la imagen de España que se desprende del discurso de Labat no es la de una España siniestra sino la de una España mal administrada y poco trabajada que, en lo tocante a prestigio, vivía de las rentas del pasado. En este sentido, Labat no hace hincapié en el fanatismo religioso, uno de los pilares del discurso de los Ilustrados sobre España y base del negrolegendarismo clásico. Si exceptuamos la evocación de la Semana Santa -que él no llegó a conocer-, con sus prácticas descritas como absurdas e hipócritas y alejadas de toda espiritualidad ${ }^{29}$, las referencias a la religión en España no traducen una imagen oscurantista ni fanática de la misma. Ciertamente, las devociones locales son presentadas a veces como producto del miedo a la Inquisición del que se aprovechaba una iglesia ávida de recaudación: «Telle la coûtume du Païs, on s'exposeroit à laisser douter de sa foi, \& passer au moins par un Maran, ou Chrétien nouveau, si on ne laissoit pas le tiers de ses biens mobiliers à l'Eglise» (Labat, 1730a: 268).

29 Labat relata que los padres dominicos quisieron convencerlo para que se quedara a ver la Semana Santa pero que, por la descripción que de ella le hicieron, no sintió el mínimo deseo de complacerlos. Sin embargo, los detalles que el autor da de esta devoción -centrados exclusivamente en la autoflagelación de los penitentes con intenciones galantes- más que de los padres dominicos, parecen provenir de otros relatos que circulaban en la época, concretamente de la Relation de Mme d'Aulnoy (1691: t.II, 158-162) con el que las coincidencias son más que evidentes. 
Sin embargo, y en primer lugar, la presión recaudatoria de la iglesia gaditana pierde fuerza como rasgo específicamente gaditano (o específicamente español) cuando se la considera dentro del marco más general del materialismo propio «des gens d'église» en el que Labat la encuadra. Esta es la razón por la que, según él, Cádiz atraía a un gran número de religiosos, que se encontraban allí «fort à leur aise»30. Por otra parte, no puede decirse que el propio Labat se mostrara ajeno a la cuestión crematística. De hecho, si algo llama la atención en la obra de este religioso es su interés por el comercio y las finanzas -a nivel local, nacional e internacional-y su habilidad para la economía doméstica.

En segundo lugar, Labat destaca la tolerancia religiosa en Cádiz, en particular con los extranjeros y por el bien del comercio, ya que los autóctonos se exponían en todo momento a las sospechas de judaísmo. El narrador no afirma abiertamente que España estuviera «llena de judíos» en la época, estereotipo antiguo por otro lado, pero lo pone en boca de terceros y lo sugiere en sus referencias a ciertas prácticas que probarían que «la Loi de Moïse est encore bien respectée en Espagne» (Labat, 1730a: 388).

On dit qu'un Espagnol étant en France, \& voyant porter le S. Sacrement sans cette escorte, disoit que les gens de sa Nation lui faisoient plus d'honneur que les François, puisqu'ils le faisoient toûjours accompagner par des gens armés; à quoi on répondit, qu'il y avoit moins d'honneur que de necessité, \& de précaution dans ce qu'on faisoit en Espagne, parce que le Païs étant plus rempli de Juifs que de Chrétiens, il étoit à craindre que le S. Sacrement ne fut insulté, au lieu qu'en France où tout le monde étoit Chrétien, cette précaution étoit inutile, parce qu'il n’y avait rien à craindre (Labat, 1730a: 273-274).

Sin embargo, más allá de algunas alusiones indirectas o burlonas, y quizá por la relación histórica de los dominicos con la Inquisición (Dedieu, 2006), Labat pasa prácticamente por alto esta cuestión sobre la que abundaron tanto los viajeros de los siglos anteriores como los Ilustrados del XVIII para describir el fanatismo y la intolerancia de los españoles.

Por último, la crueldad, otro de los rasgos característicos de la representación de los españoles en siglos anteriores, no es en absoluto un atributo del español visto por Labat. Solo la evocación de la cruenta matanza de animales para carnicería, con ayuda de perros, en un ruedo, sugiere una práctica propia de una cultura bárbara hacia la cual el narrador muestra su rechazo. Dicho sea de paso, esta sensibilidad por el sufrimiento animal que

30 «Le grand commerce qui se fait à Cadis, les embarquements pour l'Amérique, \& l'abord de toute sorte d'Etrangers y ont attirés un très-grand nombre de Prêtes et des Religieux en quantité. [...] Ils y sont tous fort à leur aise, malgré la petitesse du lieu, \& du nombre mediocre d'Espagnols qui l'habitent, marque assurée de l'opulence du Païs, de la devotion du peuple, \& du sçavoir faire des gens d'Eglise, Seculiers \& Reguliers» (Labat, 1730a: 274). 
muestra el autor en este punto no deja de contrastar con su relato de los distintos métodos para sacrificar y cocinar loros y otras aves del Nuevo Mundo, en su Nouveau Voyage aux isles de l'Amérique, relato que escandalizaría más tarde al sensible Lafcadio Hearn para quien Labat «semble avoir été doué d'un altruisme très faible; son cynisme en ce qui concerne les souffrances des animaux n'est guère compensé par la sympathie qu'il éprouve pour la douleur humaine» (Hearn, 1890: 76). En cualquier caso, los españoles pueden ser toscos e ignorantes a ojos de Labat, sobre todo entre las clases populares, pero no crueles ni sanguinarios.

En resumen, si el discurso de Labat sobre España y sobre los españoles recurre a los estereotipos más comunes de la época, no abunda sin embargo en los aspectos más sombríos de su reputación pero, dado que la ironía es uno de sus puntos fuertes, no se priva de ridiculizar las vestimentas engoladas de los autóctonos, las grandes gafas con las que pretenden aparentar erudición o la afectada gravedad de sus maneras ${ }^{31}$. Como contrapartida, el viajero aprecia ciertos hábitos locales -como la distribución de la vivienda-, elogia a las personas con las que entabla relación -el Marqués de la Rosa, el Dominico Mimbiela o los Priores de la Cartuja de Jerez y de Sevilla- y admira algunos enclaves naturales -como las cristalizaciones de la cueva de Algeciras- y la riqueza o la belleza de ciertos edificios religiosos, en particular los sevillanos.

\section{Alianzas}

La proximidad con que Labat representa a franceses y españoles en su relato y la porosidad entre ambas categorías que se desprende del mismo no excluyen la evocación de la susceptibilidad ni de la rivalidad entre ambas comunidades. De hecho, el narrador señala la hostilidad de los locales hacia los franceses, a los que tratan despectivamente de «gabachos». En este sentido puede interpretarse la anécdota de un difunto francés, expuesto al aire libre según la costumbre para aquellos que no habían satisfecho los derechos funerarios, con el fin de recaudar limosnas para sufragar los gastos del entierro:

Tout le monde s'en approchoit pour voir ce que c'étoit, pour prier ou pour jetter quelque aumône sur le corps, je m'en approchai comme les autres, il y vint une troupe

${ }^{31}$ De la misma manera que encontramos coincidencias entre ciertos detalles del relato de Labat con la Relation de Mme d'Aulnoy en la descripción de la Semana Santa, también se observa una similitud entre el primero y la carta LXXVIII de Lettres Persanes en la cuestión de las gafas. Así, en el primero, puede leerse: «Tous ceux qui se mêlent de lire \& d'écrire, jeunes \& vieux, les gens de Justice, les Medecins, les Chirurgiens, \& même les Apothicaires, les teneurs de Livres, la plupart des Ouvriers, \& generalement tous les Religieux portent de grandes lunettes, c'est pour les jeunes Religieux une marque de distinction» (Labat:1730a: 164), mientras que en el texto de Montesquieu se dice: «Les lunettes font voir démonstrativement que celui qui les porte est un homme consommé dans les sciences et enseveli dans de profondes lectures, à un tel point que sa vue en est affaiblie; et tout nez qui en est orné ou chargé peut passer, sans contredit, pour le nez d'un savant» (Montesquieu, 1721: 170). 
d'Espagnols, qui après l'avoir regardé avec quelque sorte de compassion de le voir tout couvert de sang et de blessures, demanderent qui étoit ce galant homme; mais un des assistants n'eût pas plûtôt dit que c'étoit un gavache, que ces curieux levans les yeux au Ciel, dirent en soûpirant: Plús à Dieu que ce fut le dernier ${ }^{2}$. Et s'en allerent avec un air aussi content que s'ils avoient appris le gain de quelque victoire signalée (Labat, 1730a: 272-273).

Ahora bien, si del relato de Labat no se desprende una perfecta armonía entre las dos comunidades, el siguiente episodio sugiere una relación en la que dominan los roces, las trifulcas y las reconciliaciones más que una abierta hostilidad:

Il y avoit dans la Baye de Cadis, quelques Vaisseaux de guerre François, dont la jeunesse s'avisa un jour de se promener dans les ruës avec de grandes lunettes. Les Espagnols virent bien que c'étoit pour les insulter. Ils les insulterent à leur tour, on tira l'épée, \& les Espagnols furent battus. Le Gouverneur, \& les Commandans François eurent assés de peine d'appaiser la querelle, qui pouvoit avoir de longues \& fâcheuses suites. On prétendit que les François n'avoient pris des lunettes que pour se conformer à l'usage du Païs, \& non pour insulter les Espagnols, \& comme ceux-ci avoient été les agresseurs, le Gouverneur fit mettre en prison, ceux qui furent en état d'y être mis, \& donna des gardes aux blessés, dont il en mourut deux ou trois, outre deux qui étoient restés sur le carreau. Les François eurent leurs Vaisseaux pour arrest, \& au bout de quinze jours, le Gouverneur donna un grand repas, où l'on fit une réconciliation generale, \& le Commandant de nos Navires en fit autant de son côté le jour suivant, après quoi on dispensa nôtre jeunesse de se conformer à la mode des lunettes, \& on vêcu en paix (Labat, 1730a: 264-265).

Por otra parte, el rechazo al «gabacho» que Labat pone en escena queda circunscrito a los sectores populares de la población, siendo menos perceptible, si no ausente, en las élites entre las que se mueve el autor, como lo muestra la voluntad del Marqués de la Rosa de acomodarse a las «maneras francesas» en honor de su huésped33. En reciprocidad, Labat ilustra los «defectos» del español genérico mediante escenas protagonizadas por personajes que representan a las clases populares mientras que en las élites estos defectos están prácticamente ausentes. Puede afirmarse así que, para Labat, como para muchos otros viajeros, como el barón de Bourgoing (1745-

\footnotetext{
$3^{2}$ En cursiva en el original.

33 Es destacable asimismo el importante número de españoles francoparlantes que Labat encuentra durante su estancia, sobre todo entre militares, religiosos y burócratas.
} 
1782) a finales de siglo, las élites de ambos países constituían «una misma y gran familia» (Raventós, 2007: 460). Esto indica, pues, que la oposición francés / español no es siempre un esquema estructurante del discurso de Labat sobre España y los españoles, no ya solo por porosidad antes aludida entre ambas categorías sino también por la existencia de alianzas transversales y, por así decirlo, supranacionales, que apuntan a configuraciones discursivas e identitarias diferentes de la mera nacionalidad, por ejemplo, la de la clase. En este mismo sentido, puede observarse que el «yo francés» se retrae en ocasiones en beneficio del "yo dominico», es decir, del miembro de una determinada orden religiosa que se define en relación a otras órdenes rivales. Así, el narrador se refiere a la iglesia de Santo Domingo en Cádiz como «notre église» y a los dominicos gaditanos como «nos pères» 0 «mes confrères» (Labat, 1730a: 392, 35).

Un caso ilustrativo de alianza transversal lo constituye el «Nosotros» que une al francés Labat y al español Jaime Mimbiela, «un parfaitement honnête homme, fort sçavant \& fort poli. Il paroissoit avoir beaucoup d'attachement pour Philippe $V$ \& pour la Nation Françoise, ce qui n'étoit pas un petit merite dans ce tems-là» (Labat, 1730a: 37-38). Entre ambos, que coincidieron en Cádiz de vuelta de sus respectivas misiones -Mimbiela volvía de Filipinas-, se establece una suerte de complicidad y una solidaridad no solo corporativa -ambos eran dominicos- sino también sociopolítica, basada en una común oposición a los criollos -es decir, los nacidos de padre y madre europeos en las colonias (Labat, 1730a: 53)- a los que consideraban más cercanos a los indios o a los negros que a los españoles o a los franceses «antiguos» y, por ello, inaptos para la vocación religiosa. El descubrimiento, por parte del narrador, de un sentimiento anti-criollo en Mimbiela le sirvió además como explicación retrospectiva del trato poco amable que el francés decía haber recibido del Prior del convento de Santo Domingo, a su llegada a Cádiz, y por el que se había sentido «mortifié et scandalisé» (Labat, 1730a: 4). Según esta explicación, el mencionado Prior lo habría tomado por un criollo de la Martinica y solo después de saber que era francés, nacido en Francia e hijo de franceses, habría cambiado de actitud hacia él. En cuanto a Mimbiela, Labat se lamentaba de haber perdido la ocasión, por aquel entonces, de acompañarlo «faire un tour» por México, Perú y Filipinas (Labat, 1730a: 39).

\section{Conclusiones}

En resumen, el Cádiz que Labat presenta ante los lectores y potenciales viajeros de la época es una ciudad poderosa, desde el punto de vista económico y comercial, pero vulnerable desde el punto de vista militar y poco atractiva desde el punto de vista urbanístico y cultural. Habitada y transitada por numerosos extranjeros -entre los cuales los franceses ocupaban un lugar destacado- , en su reducido recinto cohabitaban gentes de las más variadas condiciones en un régimen de vida esencialmente marítimo. Labat 
describe la bahía de Cádiz como un lugar en permanente ebullición, no solo por la dimensión transatlántica de sus relaciones sino también por su intensa actividad local, ya fuera de carácter militar, civil o religioso. En este sentido, no hay que olvidar que, por su experiencia caribeña, el viajero estaba muy familiarizado con los pequeños espacios insulares y el trasiego marítimo, con el comercio y los negocios y con el ambiente bélico internacional34. Cierto es que Labat no tenía nada que hacer en Cádiz y que el ocio obligado pudo hacerle tediosa al menos una parte de su estancia -o así es como quiso representarla veinte años después-, pero no podemos estar de acuerdo con Sarrailh cuando afirmaba que Labat se sintió en Cádiz «perdu et dépossedé» (1963: 187). Si el relato muestra en ocasiones a un narrador «très susceptible, un peu pincé, irrité par l'admiration de ses hôtes envers leurs villes» (Bennassar, 1998: 1223), también pone en escena a un personaje jovial, bromista y conversador, que aprecia el recibimiento amistoso y generoso de sus anfitriones, a pesar del exceso de chocolate, y entabla con ellos relaciones francas. La familiaridad con la que Labat se representa a sí mismo en el entorno gaditano excluye las distancias, a veces insalvables, que impone la relación exótica, en el sentido en el que aquí la entendemos. No es que los españoles no tengan «sus maneras» a las cuales Labat confiesa, aunque de manera poco convincente, que no podría adaptarse. Sin embargo, si el autor encuentra ridículas, ilógicas o toscas ciertas costumbres, en la mayor parte de los casos no pasan de ser particularidades o curiosidades que entran dentro de la variabilidad nacional sin que ello llegue a constituir un muro de incomprensión entre el viajero y los autóctonos, entre «Yo»y «Ellos». Así pues, lejos de ser un «Otro», el español es para Labat un vecino y, en todo caso, un rival histórico venido a menos pero con el que convenía entenderse y cooperar por el bien del comercio y los negocios de su país. Por último, en el relato de Labat, franceses y españoles no constituyen identidades monolíticas y excluyentes: entre ambas existe una gama de estados intermedios y de alianzas transversales que difuminan, y en ocasiones llegan a abolir, la propia oposición.

\section{REFERENCIAS BIBLIOGRÁFICAS}

34 En su semblanza del Labat antillano, Joseph Rennard escribía: «Très homme du monde,
soldat dans l'âme, il a vite fait connaissance avec les gens de mer; tous les capitaines flibus-
tiers et la plupart des commerçants sont bientôt ses amis; il est parfaitement à son aise au
milieu des marins, se comporte à bord comme un membre de l'équipage: s'il fait l'office
d'aumônier et récite la prière en public, il saura aussi, au plus fort de la tempête, boire son
coup d'eau-de-vie à la bouteille comme un bon matelot, sans se casser les dents, et, après
la bataille, il recevra sa part du pillage comme tous les flibustiers» (Rennard, 1926: 14-15). 
A. DE L. (1854): «Labat (Jean-Baptiste)», in Ferdinand Hoefer (dir.) Nouvelle biographie générale: depuis les temps les plus reculés jusqu'à nos jours. París, Firmin-Didot, t. 28, 333-335.

AgUiLÀ Solana, Irene (2007): «Voyage du P. Labat en Espagne y su traducción al español: análisis comparativo», in José M. Oliver et al. (eds.), Escrituras y reescrituras del viaje. Miradas plurales a través del tiempo y de las culturas. Berna, Peter Lang, 29-43.

Aulnoy, Mme de (1691): Relation du voyage d'Espagne. La Haya, Jacob van Ellinkhuysen [1715].

AYMES, Jean-René (2017): «Le regard porté sur Cadix et Séville par l'abbé de Vayrac et le père Labat au début du XVIII ${ }^{\mathrm{e}}$ siècle». HispanismeS, hors série, 1, 120-132.

BARTOLOMEI, Arnaud (2011): «La naturalización de los mercaderes franceses de Cádiz a finales del siglo XVIII y principios del XIX». Cuadernos de Historia Moderna, X, 123-144.

BENNASSAR, Bartholomé y Lucile BENNASSAR [eds.] (1998): Le Voyage en Espagne. Anthologie de voyageurs français et francophones du XVIe au XIX ${ }^{e}$ siècles. París, Robert Laffont.

BOLUfER PERUGA, Mónica (2003): «Civilización, costumbres y política en la literatura de viajes a España en el siglo XVIII». Estudis, 29, 255-300.

Bustos, Manuel (1984): «La ciudad de Cádiz y su contribución militar a la guerra de sucesión española (1704-1705)». Anales de la Universidad de Cádiz, 1, 139-148.

CHATILlON, Marcel (1979): Le père Labat à travers ses manuscrits. Les inédits du père Labat, Extrait du Bulletin de la Société d'histoire de la Guadeloupe, 40-42. Nérac, Imprimerie J. Owen.

Constant, Marie-Dominique (1927): «La prétendue Comédie ecclésiastique du Père Labat». Revue des Études Historiques, 93, 289-294.

DEDIEU, Jean-Pierre (2006): «La orden dominica y la inquisición en el mundo ibérico e iberoamericano», in Arturo Bernal Palacios Praedicatores, inquisitores. II. Los dominicos y la inquisición en el mundo ibérico e hispanoamericano. Sevilla, Istituto Storico Domenicano, 821-838. [Consulta en línea: https://halshs.archives-ouvertes.fr/halshs-00004698/document; 04/02/2020]

Dubost, Jean-François (1999): «Les stéréotypes nationaux à l'époque moderne (vers 1500-vers 1800)», MEFRIM, 111 (2), 667-682.

ElisABETH, Léo (s/d): «R. P. Jean-Baptiste Labat, dit "le Père Labat"». France Archives. [Consulta en línea: https://francearchives.fr/commemo/recueil2013/39388; 22/04/2020]

FOULCHÉ-DELbOSC, Raymond (1896): Bibliographie des voyages en Espagne et en Portugal. París, H. Welter.

GARCÍA CÁRCEL, Ricardo (1992): La Leyenda Negra. Historia y opinión. Madrid, Alianza Editorial. 
HALEN, Pierre (1999): «Pour en finir avec une phraséologie encombrante: la question de l'Autre et de l'exotisme dans l'approche critique des littératures coloniales et post-coloniales», in Jean-François Durand (ed.), Regards sur les littératures coloniales, I. París, L'Harmattan, 4-62.

HEARN, Lafcadio (1890): Two years in the French West Indies. New York / London, Harper \& Brothers, traducción al francés de Marc Logé: Esquisses martiniquaises, París, Mercure de France [1924].

HERZOG, Tamar (2011): «Naturales y extranjeros: sobre la construcción de categorías en el mundo hispánico». Cuadernos de Historia Moderna, X, 2-31.

JUDERÍAS, Julián (1914) La leyenda negra y la verdad histórica: contribución al estudio del concepto de España en Europa, de las causas de este concepto y de la tolerancia política y religiosa en los países civilizados. Madrid, Tip. de la Revista de Archivos.

LABAT, Jean-Baptiste (1722a): Nouveau voyage aux isles de l'Amérique. París, G. Cavelier.

LABAT, Jean-Baptiste (1722b): Voyage aux îles françaises de l'Amérique. París, Lefebvre / Ducollet (1831).

LABAT, Jean-Baptiste (1722c): Voyage aux isles de l'Amérique (Antilles). 16931705. Edición y prólogo de Albert t'Serstevens: «Vie et caractère de JeanBaptiste Labat». París, Duchartre [1931].

LABAT, Jean-Baptiste (1722d): Voyage aux Isles. Chronique aventureuse des Caraïbes. 1693-1705, edición y prólogo de Michel Le Bris: «Un sacré bonhomme». París, Phébus [1993].

LABAT, Jean-Baptiste (1730a): Voyages du P. Labat des FF Prescheurs en Espagne et en Italie, I. París, J.B \& Ch.J.B. Delespine.

LABAT, Jean-Baptiste (1730b): La Comédie ecclésiastique. Voyage en Espagne et en Italie, edición y prólogo de Albert t’Serstevens: «Le R.P. Labat». París, Grasset [1927].

LABAT, Jean-Baptiste (1730c): Voyage du P. Labat en Espagne. 1705-1706, edición y prólogo de Albert Hyrvoix de Landosle: «Notice biographique sur l'auteur». París, Pierre Roger [1927].

LABAT, Jean-Baptiste (1730d): Viaje por Andalucía. 1705-1706. Sevilla, Renacimiento, traducción de José García Mercadal, nota biográfica del traductor y prólogo de Albert t'Serstevens [2007].

LAVIGNE SAINTE-SUZANNE, Maurice de (1935): La Martinique au premier siècle de la colonisation: 1635-1742. Nantes, Imprimerie $\mathrm{M}^{\text {the }}$ Chantreau \& $\mathrm{C}^{\mathrm{ie}}$.

MÉZIN, Anne (2016): «La correspondance des consuls de France à Cadix», in Anne Mézin, y Anne Pérotin-Dumon, Le consulat de France à Cadix: Institution, intérêts et enjeux (1666-1740). Pierrefitte-sur-Seine, Publications des Archives Nationales. [Consulta en línea: http://books.openedition.org/pan/464; 15/06/2021]

MonTESQUiEu (Charles-Louis de Secondat) (1721): Lettres persanes. París, A. Lemerre [1873].

Motsch, Andreas (2014): «La relation de voyage: itinéraire d'une pratique». @nalyses. Revue critique et de théorie littéraire, 9 (1), 215-268. 
OZANAM, Didier (1968): «La colonie française de Cadix au XVIIIe siècle d'après un document inédit de 1777». Mélanges de la Casa de Velázquez, 4, 259-348.

OUELLET, Réal (2008) «Pour une poétique de la relation de voyage », in MarieChristine Pioffet (dir.), Écrire des récits de voyage (XVe-XVIII ${ }^{e}$ siècles): esquisse d'une poétique en gestation. Québec, Presses de l'Université Laval, 17-40.

PIOFFET, Marie-Christine (2011): «Les cogitations de la critique devant les fluctuations d'un 'genre': quelle poétique pour la relation de voyage?». Dix-septième siècle, 3 (252), 469-488.

RAVENTÓS BARANGÉ, Anna (2007): «El barón de Bourgoing o la pasión por la objetividad», in José M. Oliver et al. (eds.), Escrituras y reescrituras del viaje. Miradas plurales a través del tiempo y de las culturas. Berna, Peter Lang, 447-462.

RENNARD, Joseph (1927): «Le P. Labat O.P. aux Antilles», extrait de la Revue des Missions, 1/6/1926. París, Éditions Spes.

RUBIALES, Lourdes (2011): «Viaje por Andalucía de Jean-Baptiste Labat ou La traversée éditoriale d'un récit de voyages », in Virginie Coulon y Xavier Garnier (ed.), Les littératures africaines. Textes et terrains. París, Karthala, 335349.

SALAS AUSÉNS, José Antonio (2003): «Buscando vivir en la ciudad: trayectorias de inmigrantes franceses en los siglos XVII y XVIII». Revista de demografía histórica, XXI : 1, 141-165.

SARRAILH, Jean (1963): «Le voyage du Père Labat en Andalousie (Octobre 1705 Février 1706)». Annales de l'Université de Paris, 2, 169-189.

Silhouette, Etienne (1770): Voyage de France, d'Espagne, de Portugal et d'Italie. París, Merlin.

STEHLÉ, Henri (1977): «Jean-Baptiste Labat (1663-1738)», in Robert Cornevin (ed.), Hommes et Destins, París, Académie des Sciences de l'Outre-mer, 421-429.

TAMARIT, Inmaculada (2006): «Jean-Baptiste Labat en Espagne: le récit d'un séjour involontaire», in Manuel Bruña et al. (ed.), La Culture de l'autre: Espagnols en France, Français en Espagne, Sevilla, APFUE y Universidad de Sevilla, 269-277.

TESTINO-ZAFIROPOULOS, Alexandra (2008): «Representaciones imaginarias de España en Francia en el siglo XVIII. Del saber enciclopédico a los relatos de viajes», in François Delpech (ed), L’imaginaire du territoire en Espagne et au Portugal (XVI ${ }^{e}-X V I I^{e}$ siècles), Madrid, Casa de Velázquez, 19-31.

VILLARS, Pierre (1733): Mémoires de la cour d'Espagne depuis l'année 1679 jusqu'en 1681. Edición de Alfred Morel-Fatio, París, Plon, Nourrit et $\mathrm{C}^{\mathrm{ie}}$ [1893]. 